\title{
O CONHECIMENTO SOBRE O SOFTWARE KOHA NO BRASIL PELOS PROFESSORES DE BIBLIOTECONOMIA DE CURSOS PRESENCIAIS
}

KOHA SOFTWARE KNOWLEDGE IN BRAZIL BY LIBRARIANS EACHERS OF PRESENT COURSES

1 Ingrid Torres Schiessl

2 Milton Shintaku

Instituto Brasileiro de Informação em Ciência e Tecnologia1,2

Correspondência

Ingrid Torres Schiessl

Instituto Brasileiro de Informação em Ciência e

Tecnologia

Brasília, DF - Brasil.

E-mail: ingridschiessl@gmail.com

(iDORCID: https://orcid.org/0000-0001-5815-2574

Sistema de Similaridade

turnitin $\square$

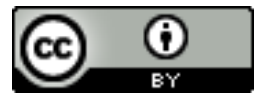

JITA: LJ. Software.

e-Location: e020005 


\section{RESUMO}

O Koha é um sistema informatizado para gestão de bibliotecas livre utilizado em todo o mundo, por todos os tipos de bibliotecas. Entretanto, nota-se que o este Sistema Integrado de Gestão de Biblioteca ainda é pouco conhecido no Brasil, podendo ser reflexo da pouca familiaridade dos alunos de biblioteconomia na vida acadêmica, na medida em que grande parte das bibliotecas universitárias brasileiras utilizam outros sistemas, principalmente os pagos. Assim, o presente estudo tem por objetivo analisar o grau de conhecimento sobre o software Koha pelos docentes do curso de graduação em Biblioteconomia no Brasil. Para tanto, utilizou-se a técnica do survey, por meio de questionário eletrônico, enviado a docentes dos cursos de biblioteconomia em todo o país. Pode-se, dessa forma, verificar que $61,4 \%$ dos professores que responderam ao questionário não conhecem o Koha. O estudo confirmou a hipótese levantada, de forma a possibilitar a criação de estratégias para a disseminação desse software aos professores.

\section{PALAVRAS-CHAVE}

Gestão de bibliotecas. Ensino de biblioteconomia. Automação de bibliotecas. Professores. Programas de curso.

\section{ABSTRACT}

Koha is a free library management system used worldwide for all types of libraries. However, this Integrated Library System is still little known in Brazil, which may reflect the education of librarians and the students lack of familiarity with the tool, as most university libraries use paid tools. Thus, the present study aims to analyze the degree of knowledge about Koha software by teachers of the undergraduate course in Library an Information Science in Brazil. A survey was sent to teachers of library and information science courses throughout the country. Thus, it verified that $61.4 \%$ of the teachers who answered the questionnaire do not know Koha. The study confirmed the hypothesis raised in order to enable the creation of strategies for the dissemination of this software to teachers.

\section{KEYWORDS}

Library science. Integrated information systems. Library automation. Academic teaching personnel. University curriculum. 


\section{RDBCI \\ Revista Digital Biblioteconomia e Ciência \\ da Informação \\ P $P O$ Digital Journal of Library and Information \\ Science}

\section{Introdução}

A mudança do físico para o digital tem alterado drasticamente o papel das bibliotecas. Entretanto, ainda é missão dessas unidades de informação gerenciar os acervos físicos (i.e. livros e periódicos impressos), pois essas publicações ainda são fonte de conhecimentos. Com isso, as bibliotecas precisam manter suas atividades primordiais alinhadas às novas atividades de publicização da informação, como destacado por Shintaku e Vidotti (2016).

As bibliotecas universitárias brasileiras verificaram uma diminuição das suas atividades tradicionais, visto a diminuição da presença dos usuários, ante a onda de informação digital e seus serviços remotos, como relata Costa (2012). Da mesma forma em que os investimentos em bibliotecas reduziram, verifica-se que esses sistemas de informação passam por necessidades, mesmo em cidades mais abastadas e em países que tradicionalmente incentivam o fomento às bibliotecas (KLINENBERG e CHIN, 2018).

Assim, as bibliotecas enfrentam desafios em manter os seus serviços tradicionais de gestão de acervo físico e os novos digitais, com orçamento cada vez menor. Uma das suas estratégias é o uso de software livre para a oferta de serviços. Sendo o maior destaque o uso do software livre DSpace para a criação de repositórios e bibliotecas digitais, e no caso das bibliotecas universitárias para disseminação de teses e dissertações.

Entretanto, para a gestão do acervo físico, a presença de software livre ainda é modesta, tanto que Schiessl et al (2016) verificaram que a maioria das bibliotecas universitárias brasileiras utilizam Sistemas Integrados de Gestão de Bibliotecas (SIGB) proprietários, destacando o uso para o software Pergamum. No Brasil, o uso de ferramentas proprietárias pode ter razões históricas, na medida em que os sistemas livres, baseados no Computerized Documentation System / Integrated Set of Information System (CDS/ISIS), se tornaram obsoletos e desde então não se apresentou outra ferramenta livre, levando as instituições a aderirem aos softwares licenciados.

Se no Brasil muitas instituições aderiram a softwares pagos, no mundo há uma grande parcela que adota o software livre Koha. Destaque para as bibliotecas públicas, visto que países como Turquia e Filipinas adotaram o Koha como ferramenta oficial para todas as suas bibliotecas públicas, tornando-se países com o maior número de instalações do Koha (BIBLIOTECA NACIONAL, 2009; YAZICIOGLU, 2018; BREEDING, 2019).

Nesse contexto, o presente estudo se objetiva a verificar uma das possíveis causas da pequena adoção do Koha no Brasil, cuja hipótese se encontra na pouca disseminação dessa ferramenta entre os docentes de biblioteconomia no país. Assim, como os docentes não estão familiarizados com o Koha, não repassam aos discentes, provocando a pouca divulgação dessa ferramenta entre os profissionais de biblioteca. 


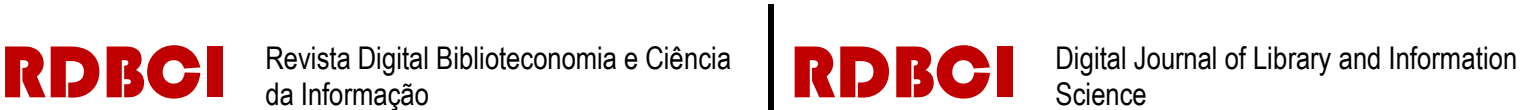

\section{Cursos de Biblioteconomia no Brasil}

A história do curso de biblioteconomia no Brasil nasce no início do século XX, em 1911, sendo ofertado na Biblioteca Nacional do Rio de Janeiro, oficializado pelo Decreto $\mathrm{n}^{\circ} 8.835$ de 11 de julho de 1911. Neste curso inicial, foi dada oportunidade aos estudantes de outros curso e profissionais, o quais já atuavam em bibliotecas, a se graduar como bibliotecários. Weizel (2009) relata que o curso teve influências de linhas europeias, seguindo o modelo de ensino e prática profissional da École de Chartes, na França. Em 1969, o curso dado pela Biblioteca Nacional passou para a Universidade Federal do Estado do Rio de Janeiro (UNIRIO).

No Brasil, Fonseca (1974) entende que o ensino da Biblioteconomia pode ser dividido em três fases. A primeira fase foi quando predominou a influência francesa e a liderança era da Biblioteca Nacional, período de 1879 a 1929. A segunda, de 1929 a 1962, desenvolveu-se sob a influência inovadora de um curso fundado em São Paulo, sob direta inspiração norteamericana. E a terceira, a partir de 1962, caracterizou-se pela uniformidade dos cursos desenvolvidos a partir do currículo mínimo. Mueller (1985) relata que evolução do ensino de Biblioteconomia no Brasil progrediu de maneira rápida, impulsionada por fatores internos e externos à biblioteca. No entanto, a autora alega que o é imprescindível o entendimento da profissão a curto e médio prazo, pois as responsabilidades profissionais são amplas e é preciso preparar profissionais para atuarem em situações, que variam das mais sofisticadas às mais primitivas.

A profissão do bibliotecário tem os direitos resguardados por lei. No ano de 1962, foi homologada a Lei $\mathrm{n}^{\circ} 4.084$, a qual dispõe sobre a profissão de bibliotecário e regulamenta o seu exercício e, em 1998, há a atualização dos exercícios da profissão pela Lei no 9.674. O mercado profissional oferece oportunidades para a profissão, destaca-se a Lei ${ }^{\circ} 12.244$ de 24 de maio de 2010 (Lei da Biblioteca), a qual regula as bibliotecas escolares e exige a presença dos bibliotecários até 2020. Com isso abre-se uma grande oportunidade para os bibliotecários visto a quantidade de escolas existentes no país.

Nesse contexto, a Coordenação de Aperfeiçoamento de Pessoal de Nível Superior (CAPES), fomentou a criação de cursos de bacharelado em biblioteconomia, na modalidade à distância (EAD), por meio da Universidade Aberta do Brasil (UAB), de forma a atender a Lei da Biblioteca. Em 2019, há registrados no Ministério da Educação (MEC) 589 cursos de biblioteconomia em nível de graduação, desse total 546 representam cursos com educação à distância e 46 cursos de educação presencial (BRASIL, 2019). Cabe ressaltar que o portal eMEC é regulamentado pela Portaria Normativa n ${ }^{\circ} 21$, de 21 de dezembro de 2017, como base de dados oficial dos cursos e Instituições de Educação Superior (IES).

Pode-se, por motivos estruturais, dividir a história dos cursos de biblioteconomia em três etapas, sendo a gênese, o amadurecimento e a inovação. Se no início foi pioneiro em um Brasil com poucos cursos superiores, ofertado pela Biblioteca Nacional, amadureceu com os cursos

e019004




\section{RPBO $\begin{aligned} & \text { Revista Digital Biblioteconomia e Ciência } \\ & \text { da Informação }\end{aligned}$ RPBO $\begin{aligned} & \text { Digital Journal of Library and Information } \\ & \text { Science }\end{aligned}$}

presenciais, principalmente dado pelas universidades federais, e agora inova ao ser democratizado pelo ensino a distância, que retira as limitações de espaço e tempo dos cursos presenciais.

Entretanto, há a preocupação com a formação dos profissionais no que tange às novas tecnologias, visto que o mercado de trabalho se apresenta amplo, ao considerar as mudanças na sociedade, e o bibliotecário precisa ser um profissional flexível, adaptável e conectado com as necessidades dos usuários ou interagentes (SOUZA, 2018). Portanto, se faz importante a capacidade de adaptação às demandas da contemporaneidade e às novas competências requeridas para o desempenho de atividades, como o conhecimento em técnicas de comunicação, interação, informática e gestão. Além disso, os diálogos com profissionais de outras áreas podem trazer mais oportunidades que ameaças.

Nesse sentido, mesmo que os bibliotecários não utilizem ferramentas livres ou proprietárias em suas atividades, é importante que as conheçam principalmente durante na sua formação, de forma a possibilitar a visão crítica perante aos softwares para gestão de bibliotecas. O Koha, por exemplo, é pouco conhecido por alguns bibliotecários, mesmo sendo a ferramenta livre mais utilizada no mundo para gestão de bibliotecas, sendo que em 2020 completa 20 anos de seu lançamento, possuindo atualizações constantes, que o mantém atual, mesmo com os avanços tecnológicos.

\section{Koha}

O Koha é um software livre estruturado em módulos, que são capazes de atuar em diversas tarefas diárias da biblioteca, como: Circulação, Gerenciamento de Usuários, Catalogação, Autoridades, Aquisição, Periódicos, Criação de Relatórios, Ferramentas, Administração e um catálogo online. Ademais, possui uma comunidade internacional ativa onde discute-se, compartilha-se e debatem-se questões sobre as funcionalidades, os erros, o uso e as novas ferramentas desenvolvidas, visando uma melhor performance do software (SCHIESSL; BRASILEIRO; MACEDO, 2019).

Schiessl, Brasileiro e Macêdo (2019) relatam que o Koha foi implementado primeiro na biblioteca Horowhenua Library Trust, na Nova Zelândia, e o fato de possuir código aberto contribuiu para sua disseminação nos anos seguintes à sua implantação. Os autores afirmam que com o crescimento do uso do sistema, também ocorre uma expansão da sua rede de suporte, caracterizada, principalmente, pela ajuda mútua de seus usuários.

O Koha é o software livre para bibliotecas mais utilizado mundialmente, países como a Turquia e as Filipinas, por exemplo, adotam o Koha em todas as suas bibliotecas públicas (SCHIESSL et al, 2017). As autoras Yang e Hoffman (2010) consideram o Koha mais 


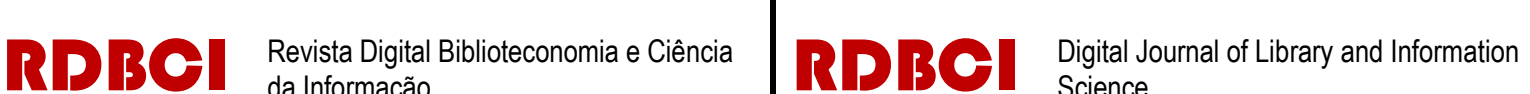

vantajoso entre os softwares livres, visto que atende a grande parte dos critérios técnicos. Em países menos desenvolvidos, o Koha se mostra uma opção por ser gratuito, os autores Egundjobi e Awoyemi (2012) analisam o uso da ferramenta na Nigéria e apontam que há uma satisfação com o software por parte da equipe de bibliotecários. Anuradha, Sivakaminathan e Arun Kumar (2011) evidenciam que o Koha pode integrar-se a outros softwares livres, de forma a ampliar os serviços ofertados, principalmente a integração com funcionalidades voltadas a gestão de textos integrais digitais.

Outro aspecto discutido é a migração de dados, Walls (2011) aponta que a migração para o Koha não apresenta grandes problemas, pois a ferramenta utiliza o padrão MARC, contudo o autor afirma que toda migração de dados requer atenção, pois é comum encontrar algumas dificuldades e desafios durante o processo de transferência de informação.

Apesar de ser criado para uma biblioteca pública, o Koha se mostra versátil e pode ser utilizado em outros tipos de biblioteca. No Brasil, Fernandez (2013) apresentou o uso do Koha em bibliotecas públicas, enquanto Figueiredo (2015) em biblioteca escolar. Em Portugal, Amante e Marçal (2012) relatam o uso do software nas bibliotecas universitárias. De forma que o Koha se apresenta como um software adaptável aos diferentes tipos de bibliotecas, sendo assim uma opção de solução tecnológica para o universo bibliotecário. Apesar da flexibilidade, no Brasil, o Instituto Brasileiro de Informação em Ciência e Tecnologia apresenta na sua página wiki uma lista de apenas oito instituições que utilizam o software Koha, sendo que não há no país outra plataforma que realiza a contagem de instituições que usam essa ferramenta.

\section{Metodologia}

O objetivo do presente estudo é de verificar razões pelo pouco uso do Koha no Brasil. Uma vez que é a ferramenta livre mais utilizada no mundo, mas no Brasil é pouco utilizado. Nesse sentido, o presente estudo pode ser classificado como descritivo, pois procura descrever um fenômeno, por meio do estudo de variáveis, alinhado aos conceitos apresentados por Gil (2008). Assim, o estudo levanta variáveis quantitativas como quantidade de docentes que conhecem o Koha ou que a utilizam como ferramenta de apoio ao ensino.

Quanto a abordagem, o estudo possui aspectos mistos, visto que as abordagens se complementam, com a coleta de dados de caráter quantitativa e uma análise predominantemente qualitativa. Essa abordagem mista encontra alinhamento com os propostos de Creswell (2010).

Nesse ponto, a técnica de coleta de dados utilizada é o survey, que possibilita a integração de coleta de variáveis quantitativas e qualitativas. Assim, questões de múltipla escolha ou seleção, que procura frequência (quantitativo), e questões abertas em que podem ser respondidos de forma livre (qualitativo) compõe um questionário online a ser respondido 


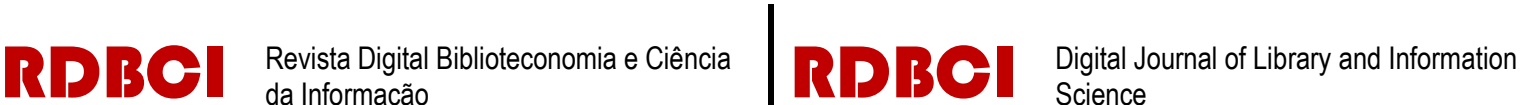

pelos professores de biblioteconomia de cursos ofertados no Brasil, conforme os objetivos da pesquisa. As questões abertas eram do tipo resposta curta, sendo que apenas as duas primeiras perguntas foram respondidas por todos os participantes, essas são: Qual a instituição que atua? e Quanto tempo de docência? As outras duas perguntas, dependiam exclusivamente da resposta do participante, quem responde a questão três não responde a número quatro e vice-versa. A questão aberta número três, dependia da resposta de múltipla escolha número três, a qual questionava se o docente tinha conhecimento sobre o SIGB, caso negativa era possível enviar as informações de contato para receber mais informações (pergunta é Por qual meio gostaria de obter informação? (Indique informações para contato). Enquanto, a última questão é destinada para que o docente informe o nome da disciplina, na qual o software Koha é utilizado, de forma a possibilitar e verificar o cenário sobre o conhecimento deste SIGB no ensino de biblioteconomia.

O questionário online foi desenvolvido de forma simples para ser respondido em média de três minutos, composto de cinco seções. Nem todos os respondentes percorrerão todas as perguntas. As respostas positivas levam a outras perguntas, com objetivo de verificar o conhecimento dos docentes em relação ao Koha.

$\mathrm{O}$ estudo se restringe aos professores dos cursos presenciais, na medida em que muitas instituições ofertam o presencial e a distância, alguns docentes participam das duas modalidades. Em 2019, há registrados no Ministério da Educação (MEC) 589 cursos de biblioteconomia em nível de graduação, desse total 546 representam cursos com educação à distância e 46 cursos de educação presencial (BRASIL, 2019). Cursos presenciais são mais tradicionais e atuaram na formação de grande parte dos profissionais, visto que a o curso de biblioteconomia EAD da CAPES iniciou-se em 2018, não tendo ainda formado profissionais. Utilizou-se do portal e-MEC, pois é base de dados oficial dos cursos e Instituições de Educação Superior (IES).

Dos 410 professores identificados nos sites institucionais dos cursos presenciais, apenas 107 professores disponibilizavam o e-mail. Importa ressaltar, que da listagem de professores foi possível identificar quatro professores que ocupavam o cargo de coordenação, por isso, o e-mail disponibilizado era o da coordenação, é provável que esses docentes tenham encaminhado o questionário para os outros docentes. Além disso, o questionário era público, qualquer pessoa com acesso ao link poderia responde-lo, de forma que os docentes poderiam encaminha-lo para os colegas, os quais não foram alcançados pelos autores desse estudo. Por fim, obteve-se 70 respostas, entre o período 14 de março de 2019 a 01 de julho de 2019. 


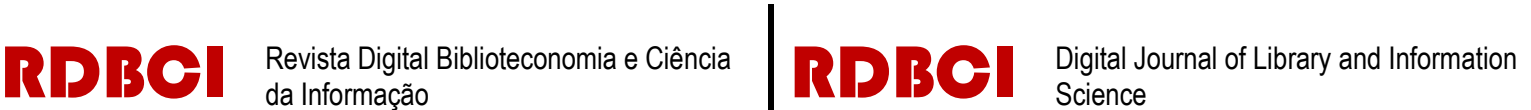

\section{Resultados}

O estudo iniciou levantando os cursos presenciais de biblioteconomia por meio do Portal e-MEC, na plataforma há 47 cursos presenciais de biblioteconomia, sendo que 4 cursos estão em processo de desativação, extinção e/ou descredenciamento voluntário, desta forma o total são 43 cursos presenciais de biblioteconomia. Observa-se que nem todos os estados brasileiros ofertam curso de biblioteconomia presencial como Acre, Amapá, Mato Grosso do Sul, Roraima e Tocantins. Por outro lado, São Paulo é o estado que mais ofertam cursos presenciais, tendo oito instituições ofertando o curso. Esses dados revelam certa deficiência na oferta de cursos no país, se comparar com outros cursos presenciais, como direito, engenharia e medicina, porém justifica o fomento da CAPES ao curso à distância de Biblioteconomia pela UAB.

As universidades públicas se destacam na formação de bibliotecários de forma presencial, sendo que as federais ocupam $61 \%$ das instituições. Cinco Universidades Estaduais também ofertam cursos, destacando a Universidade de São Paulo (USP) e Universidade Estadual Paulista Júlio de Mesquita Filho (UNESP) pelo corpo docente, composto por professores de renome, todos com o grau de doutores, além de figurarem entre as melhores universidades do país.

No presente estudo recebeu-se 70 respostas no período de 14 de março de 2019 a 01 de julho de 2019, sendo convidados professores de todas as instituições que ofertam o curso presencial de biblioteconomia, por meio de e-mail diretamente aos docentes e aos coordenadores de curso. As respostas vieram de 23 instituições, totalizando 65 respostas, sendo que a Universidade Federal da Paraíba (UFPB) foi a que mais participou, com 15 respostas e; sete instituições responderam apenas uma vez, isto é, apenas um docente respondeu ao questionário.

Quanto ao tempo de docência, têm-se respostas variadas, desde professores com 40 anos de magistério até novatos com menos de um ano. Nove respondentes afirmaram que possuem 10 anos de trabalho, o maior quantitativo. Entretanto, 55 respondentes possuem menos de cinco anos de docência, revelando uma amostra de professores novos, ainda com pouco tempo de atuação, possivelmente abertos ao uso de novas tecnologias, visto que ultimamente há uma grande demanda por ferramentas nas bibliotecas.

A caracterização dos dados revela que os respondentes do survey são professores majoritariamente com até cinco anos de docência, vinculado a 22 instituições de ensino distribuídos por vários estados brasileiros. Esses resultados podem sugerir que professores com atuação mais recente estão mais disponíveis a atender a pesquisas, por meio de respostas a questionários online. Entretanto, esse ponto requer estudos mais aprofundados, pois, pode remeter a familiaridade com a tecnologia, disponibilidade de tempo, entre tantos outros fatores.

Quanto ao conhecimento sobre o SIGB Koha verificou-se que 62,8\% dos respondentes 


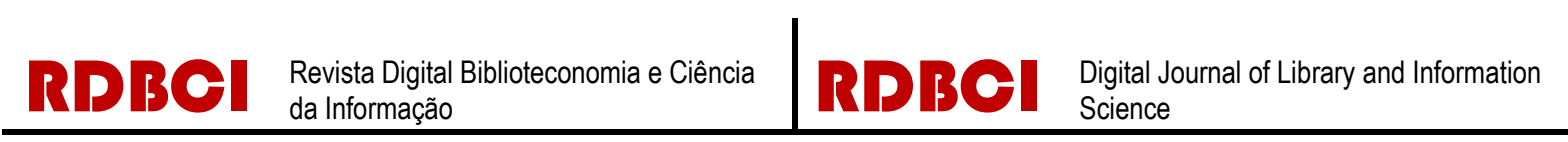
desconhecem esse sistema e apenas $37,1 \%$ o conhecem, revelando pouca divulgação da ferramenta entre os professores. Entretanto, quase um terço dos professores que responderam não conhecer o Koha, gostariam de ter maiores informações sobre a ferramenta. Esse indício parece refletir a pouca participação do Koha na vida acadêmica dos professores, visto que, como apresenta Marques e Saldanha (2018), a tecnologia é um dos eixos de estudo da biblioteconomia e ciência da informação. Assim, pode ser que outras ferramentas sejam mais conhecidas por fazerem parte das bibliotecas e dos cursos de formação dos professores, como é o caso da ferramenta Pergamum, que Schiessl et al (2016) verificou ser a mais utilizadas nas bibliotecas universitárias.

O desconhecimento de várias ferramentas de gestão de biblioteca pode ter relação ao que Madureira e Vilarinho (2010) relatam como a falta de apoio do setor de informática para com a biblioteca. Destaca-se que para ensinar ferramentas de gestão, o curso de biblioteconomia precisa de laboratórios de informática com apoio da equipe de informática da universidade

Com relação ao Koha, para os respondentes que afirmaram ter conhecimentos sobre a ferramenta, a maioria apenas ouviu falar (gráfico 1). Contudo, os professores tiveram a oportunidade de ensinar algo sobre o Koha por meio de treinamentos/aula.

Gráfico 1. Como você categoriza o seu conhecimento sobre o Koha?

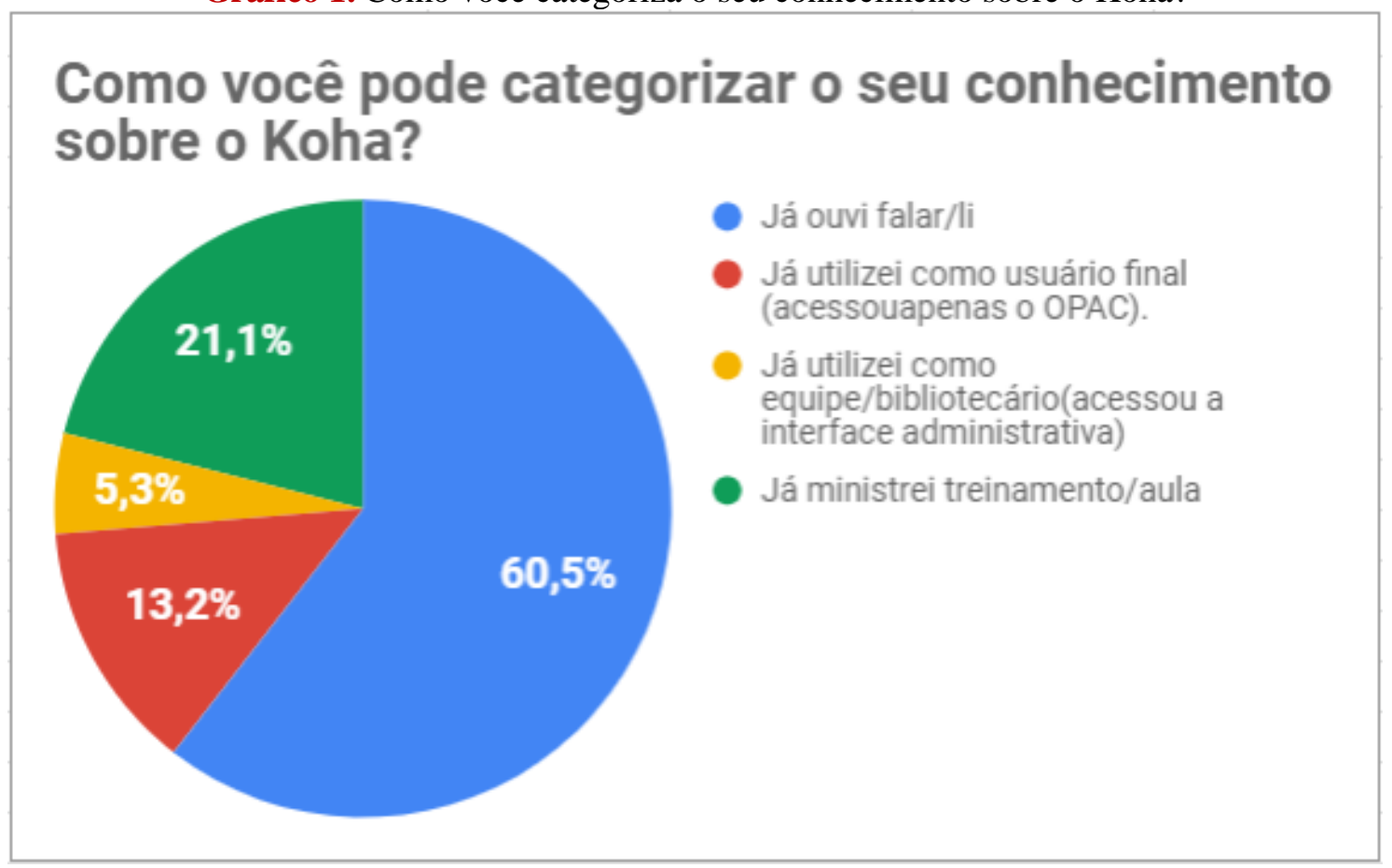

Fonte: Elaboração dos autores (2019).

Apenas dez professores responderam já ter ministrado aulas tendo o Koha como conteúdo. Assim, ao ser inquirido sobre como foi ministrado a aula, oito responderam ter aplicado treinamentos práticos. Esse indício parece promissor, mesmo com um pequeno 
quantitativo, os professores que conhecem a ferramentas oferecem treinamento prático, o que pode-se inferir que o Koha pode ser uma boa ferramenta didática para a formação de bibliotecários.

No que se refere aos módulos do Koha, o mais utilizado nos treinamentos (gráfico 2) é o módulo de catalogação, sendo natural, visto que o processamento técnico faz parte das tarefas dos bibliotecários. Catalogar, colaborativamente ou não, é uma atividade comum nas bibliotecas e o Koha implementa todas as funcionalidades para o processamento técnico.

Gráfico 2. Como você categoriza o seu conhecimento sobre o Koha?

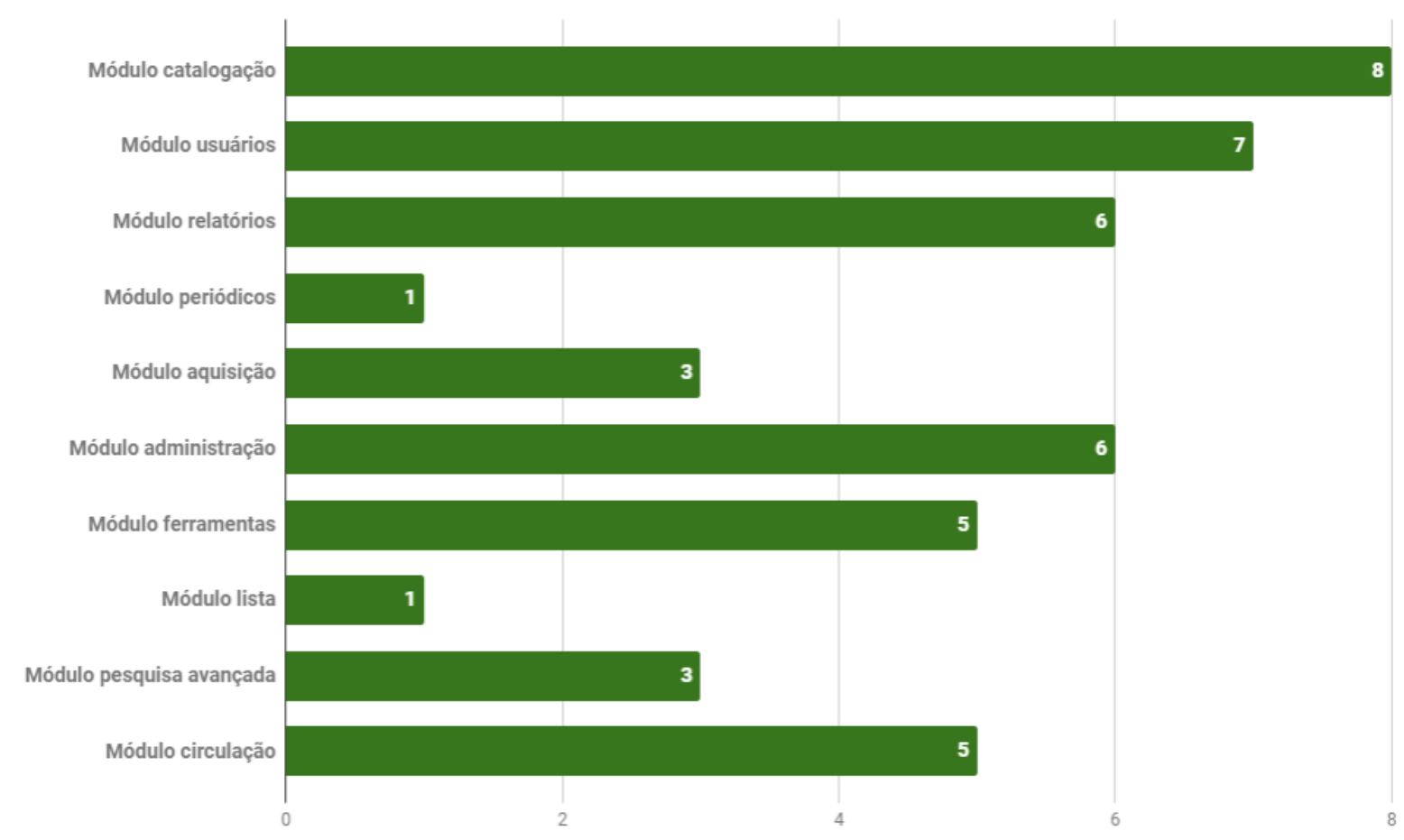

Fonte: Elaboração dos autores (2019).

Outro ponto observado é o módulo de periódicos, que não é muito utilizado nos treinamentos práticos ofertados pelos docentes. Esse fato pode ser estar relacionado ao fato que os cada vez mais os periódicos se consolidam em meio digital, como afirma Meadows (2001). No caso do software Koha, o módulo de periódicos foi criado para gestão de assinaturas de periódicos impressos (SCHIESSL et al, 2017). Como defendem Shintaku e Vidotti (2016), bibliotecários necessitam ter maiores conhecimentos sobre publicização de conteúdos digitais, visto que as informações nesse suporte estão se tornando mais comuns.

Os resultados desse estudo, mesmo sendo uma parcela da comunidade de docentes do curso presencial de biblioteconomia, encontra paralelos com o que Souza e Fujino (2009) relatam no que concerne aos desafios na formação dos bibliotecários em relação à tecnologia. O Koha não é uma tecnologia muito nova, pois foi criado no ano 2000, mas ainda é pouco conhecido pelos professores brasileiros participantes da pesquisa, apesar de apresentar vantagens por ser um software livre, alinhado com tendências como a da Ciência Aberta. 


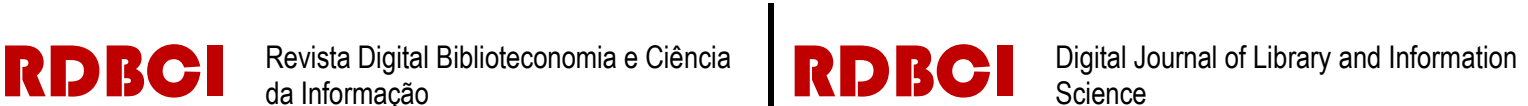

Mesmo que os resultados do estudo sejam uma parcela da comunidade de professores de biblioteconomia atuando no país pode revelar indícios que o desconhecimento por parte dos docentes sobre o Koha seja um fator do pouco uso desse software nas bibliotecas. Outro ponto importante é a pouca literatura técnica sobre a ferramenta em português, a qual professores podem utilizar como material didático, em que somente em 2017 foi publicado o Guia de usuário do Koha, pelo Instituto Brasileiro de Informação em Ciência e Tecnologia.

\section{Considerações Finais}

A formação dos profissionais, mesmo que não se finda ao término de um curso, é importante em vários aspectos. Muito do conhecimento sobre a profissão é garantida durante o percurso acadêmico. Assim, o presente estudo se objetivou a verificar se o baixo uso do Koha, no Brasil, tinha uma relação com o desconhecimento dos professores de biblioteconomia. Os resultados apresentaram indícios que essa relação pode ser válida, visto o pouco conhecimento dos discentes que participaram do estudo.

A formação acadêmica e profissional do bibliotecário enfrenta desafios com novas tecnologias, tanto que Madureira e Vilarinho (2010) discutem a questão das bibliotecas digitais, que não são contempladas no curso, mas são realidade na vida profissional. Araújo (2018) defende uma mudança no ensino de biblioteconomia diante dos desafios impostos pela tecnologia, mas admite que deve-se manter certos estudos tradicionais, na medida em que a disciplina é plural. Assim, manter o ensino de atividades voltadas a gestão de acervo físico, por meio de ferramenta informatizada, ainda é um tema atual e deve ser aprimorado com a adição de novas tecnologias.

Nesse contexto, o presente estudo aponta indícios que relacionam a pouca familiarização dos professores de biblioteconomia com a ferramenta koha, que pode ter influências na formação dos novos profissionais de biblioteca. Da mesma forma em que grande parte dos professores não conhecem o Koha, grande parte dos cursos de biblioteconomia são ofertados por instituições públicas que utilizam ferramentas pagas, diminuindo a possibilidade de contato dos discentes com o Koha.

Por outro lado, grande parte dos usuários que declararam conhecer o Koha, utilizou-o como recurso didático para ministrar aulas, o que pode representar um bom indício. Assim, pode-se dizer, que falta uma boa divulgação do Koha nos cursos de biblioteconomia e nos eventos da área, com ações voltados especialmente para os professores, de forma a atender a parcela que não tem familiaridade com a ferramenta.

Com isso, nota-se que a inserção do Koha nos currículos dos cursos de biblioteconomia pode fortalecer a comunidade de usuários no Brasil, na medida em que é um software livre, condizente com as orientações da ciência aberta e indicação governamental, indicada Instrução Normativa $\mathrm{n}^{\circ} 04$ (IN04), que trata da contratação de licenças de software. Atende as necessidades de gestão do acervo físico, nos serviços tradicionais da biblioteca.

\begin{tabular}{l|c|c|c|c|c}
\hline () RDBCl: Rev. Digit. Bibliotecon. Cienc. Inf. & Campinas, SP & v.18 & $1-15$ & e019004 & 2020 \\
\hline
\end{tabular}


Não se pode relegar a tradição da biblioteca como custodiadora do conhecimento impresso. Silva e Cunha (2002), discutindo sobre a formação dos bibliotecários do século XXI, defendem que é preciso humanizar o ensino, de forma a ter profissionais mais adequado ao uso de tecnologia, de forma a mediar a informação. A tecnologia deve ser utilizada como uma ferramenta, tendo o seu espaço nas atividades, no qual os bibliotecários devem agregar novos serviços, mas mantendo os tradicionais, tendo o Koha como uma das opções.

\section{Referências}

AMANTE, Maria João; MARÇAL, Bruno. Dinâmicas de implementação de software open source numa Biblioteca Universitária: o caso do ISCTE-IUL. In: CONGRESSO NACIONAL DE BIBLIOTECÁRIOS, ARQUIVISTAS E DOCUMENTALISTAS, 11., 2012, Lisboa. Anais [...]. Lisboa: Associação Portuguesa de Bibliotecários, Arquivistas e Documentalistas (BAD), 2012. Disponível em:

https://www.bad.pt/publicacoes/index.php/congressosbad/article/view/417. Acesso em 31 jul. 2019.

ANURADHA, K. T.; SIVAKA MINATHAN, R.; ARUN KUMAR, P. Open-source tools for enhancing full-text searching of Opacs: use of Koha, Greenstone and Fedora. Program: Electronic Library and Information Systems, v. 45, n.2, p. 231-239, 2011. Disponível em: https://www.bad.pt/publicacoes/index.php/congressosbad/article/view/417. Acesso em 31 jul. 2019.

ARAÚJO, Carlos Alberto Ávila. Biblioteconomia: fundamentos e desafios contemporâneos. Folha de Rosto, v. 3, n. 1, p. 68-79, 2018. Disponível em: http://www.brapci.inf.br/index.php/res/download/52697. Acesso em 31 jul. 2019.

BIBLIOTECA NACIONAL (Filipinas). Country reports: National Library of the Philippines. In: CONFERENCE OF DIRECTORS OF NATIONAL LIBRARIES IN ASIA AND OCEANIA (CDNLAO), 17., 2009, Hanoi, Vietnã. Relatórios [...]. Tóquio: National Diet Library, 2009. Disponível em: https://www.ndl.go.jp/en/cdnlao/meetings/2009.html Acesso em: 31 jul. 2019..

BRASIL. Cadastro e-MEC: cadastro nacional de Cursos e Instituições de Educação Superior. 2019. Disponível em: http://emec.mec.gov.br/. Acesso em 31 jul. 2019.

BREEDING, M. Map of Libraries: the library automation system used is Koha. Disponível em: https://librarytechnology.org/libraries/map.pl?ILS=Koha. Acesso em: 31 jul. 2019.

CHAUHAN, Kaushal. Evaluation in use of KOHA Library Management Software in OPJGU, Sonipat. Library Philosophy and Practice, p. 1-13, 2018. Disponível em: https://digitalcommons.unl.edu/libphilprac/2070/. Acesso em 31 jul. 2019.

COSTA, Maira Murrieta. As bibliotecas brasileiras em 2018: resultados da técnica de delfos. Perspectivas em Ciência da informação, v. 17, n. 1, p. 74-93, 2012. Disponível em: 
http://portaldeperiodicos.eci.ufmg.br/index.php/pci/article/view/1363. Acesso em 31 jul. 2019.

CRESWELL, John W. Projeto de pesquisa: métodos qualitativo, quantitativo e misto. Porto Alegre: Artmed: 2010. 296 p.

EGUNJOBI, R. A.; AWOYEMI, R. A. Library automation with Koha. Library Hi Tech News, v. 29, n. 3, p. 12-15, 2012.

EYLER, Pat. Koha: a gift to libraries from New Zealand. Linux Journal, v. 2003, n. 106, 1 fev. 2003. Disponível em: https://www.linuxjournal.com/article/6350. Acesso em 31 jul. 2019.

FERNANDEZ, Rafael Saad. O uso de softwares livres na gestão pública de acervos informacionais: o caso do Koha nas bibliotecas de São Bernardo do Campo. Informação \& Informação, v. 18, n. 2, p. 231-248, 2013. DOI: 10.5433/1981-8920.2013v18n2p231. Disponível em: http://www.uel.br/revistas/uel/index.php/informacao/article/view/16174. Acesso em 31 jul. 2019.

FERNÁNDEZ-ALFARO, Leonor; MÁRQUEZ-PÉREZ, Aurora; CHAMORRORODRÍGUEZ, Ricardo. Implementación de Koha en la Biblioteca de la Universidad de Cádiz. El profesional de la información (EPI), v. 27, n. 4, p. 928-936, 2018. Disponível em: http://www.elprofesionaldelainformacion.com/contenidos/2018/jul/21.pdf. Acesso em 31 jul. 2019.

FIGUEIREDO, Marcia Feijão de. Análise do aplicativo Koha no Colégio Pedro II: um relato de experiência. RDBCI: Revista Digital de Biblioteconomia e Ciência da Informação, v. 13, n. 3, p. 653-665, 25 set. 2015. DOI: 10.20396/rdbci.v13i3.2125. Disponível em: https://periodicos.sbu.unicamp.br/ojs/index.php/rdbci/article/view/2125. Acesso em 31 jul. 2019.

GIL, Antonio Carlos. Métodos e técnicas de pesquisa social. 6. ed. São Paulo: Atlas, 2008. $216 \mathrm{p}$.

KLINENBERG, Eric; CHIN, Credit Louie. To restore civil society, start with the library. The New York Times, v. 8, 2018. Disponível em: https://www.nytimes.com/2018/09/08/opinion/sunday/civil-society-library.html. Acesso em 31 jul. 2019.

MADUREIRA, Helania Oliveira; VILARINHO, Lúcia Regina Goulart. A formação do bibliotecário para atuar em bibliotecas virtuais: uma questão a aprofundar. Perspectivas em Ciência da Informação, v. 15, n. 3, p. 87-106, 2010. Disponível em: http://portaldeperiodicos.eci.ufmg.br/index.php/pci/article/view/1077. Acesso em 31 jul. 2019.

MARQUES, Tathiane Amaral; SALDANHA, Gustavo Silva. Saberes e fazeres em transformação: a produção do conhecimento em Biblioteconomia e Ciência da Informação no Brasil a partir dos anais de eventos científicos dos anos 1970. RBBD: Revista Brasileira de 


\section{RDBCI \\ Revista Digital Biblioteconomia e Ciência \\ da Informação

Biblioteconomia e Documentação, v. 14, p. 110-138, 2018. Disponível em:

https://rbbd.febab.org.br/rbbd/article/view/1082. Acesso em 31 jul. 2019.

MEADOWS, Jack. Os periódicos científicos e a transição do meio impresso para o eletrônico. Revista de Biblioteconomia de Brasília, Brasília, v. 25, n. 1, p. 5-14, 2001. Disponível em: http://www.brapci.inf.br/_repositorio/2010/10/pdf_29f176742d_0012269.pdf. Acesso em 31 jul. 2019.

MUELLER, Suzana Pinheiro Machado. O ensino de biblioteconomia no Brasil. Ciência da Informação, v. 14, n. 1, 1985. Disponível em: http://revista.ibict.br/ciinf/article/view/222. Acesso em 31 jul. 2019.

SCHIESSL, Ingrid Torres; BRASILEIRO, Italo Barbosa; MACÊDO, Diego José. Koha: Sistema de Biblioteca da SNJ. In: SHINTAKU, Milton; BRITO, Ronnie Fagundes de; BARCELOS, Janinne (org.). Soluções Tecnológicas para Gestão do Conhecimento sobre Juventude. Brasília: Ibict, 2019.p. 65 - 76. Disponível em: http:/livroaberto.ibict.br/handle/123456789/1078. Acesso em 31 jul. 2019..

SCHIESSL, Ingrid Torres et al. Cenário Brasileiro dos catálogos on-line das bibliotecas universitárias federais. Revista Conhecimento em Ação, n. 2, v. 1, p. 111-126, jul./dez. 2016. Disponível em: https://revistas.ufrj.br/index.php/rca/article/view/111/7153. Acesso em: 04 jul. 2019.

SCHIESSL, Ingrid Torres et al. Implantação do sistema de gestão de biblioteca Koha na biblioteca de juventude da SNJ. In: CONGRESSO BRASILEIRO DE BIBLIOTECONOMIA E DOCUMENTAÇÃO, 27., 2017, Fortaleza. Anais [...]. Fortaleza: Febab, 2017. Disponível em: https://portal.febab.org.br/anais/article/view/1986. Acesso em: 04 jul. 2019.

SHINTAKU, Milton; VIDOTTI, Silvana Aparecida Borsetti Gregorio. Bibliotecas e repositórios no processo de publicação digital. BIBLOS, [S.1.], v. 30, n. 1, p. 61-80, nov. 2016. ISSN 2236-7594. Disponível em: https://periodicos.furg.br/biblos/article/view/5762. Acesso em: 04 jul. 2019.

SILVA, Edna Lúcia da; CUNHA, Miriam Vieira da. A formação profissional no século XXI: desafios e dilemas. Ciência da informação, v. 31, n. 3, 2002. Disponível http://revista.ibict.br/ciinf/article/view/950. Acesso em: 31 jul. 2019.

SOUSA, Margarida Maria de; FUJINO, Asa. A biblioteca universitária como ambiente de aprendizagem no ensino superior: desafios perspectivas. In: ENCONTRO NACIONAL DE PESQUISA EM CIÊNCIAS DA INFORMAÇÃO, 5., 2009, João Pessoa. Anais [...] . João Pessoa: ENANCIB, 2009. p. 1780 - 1798. Disponível http://enancib.ibict.br/index.php/enancib/xenancib/paper/viewFile/3278/2404. Acesso em: 31 jul. 2019.

SOUZA, Katyusha Madureira Loures de. Mercado de trabalho do bibliotecário do século XXI. In: RIBEIRO, Anna Carolina Mendonça Lemos; FERREIRA, Pedro Cavalcanti Gonçalves (org.). Bibliotecário do século XXI: pensando o seu papel na contemporaneidade. 
Brasília: Ipea, 2019. p. 83-96. Disponível em:

http://repositorio.ipea.gov.br/handle/11058/8298. Acesso em: 04 jul. 2019.

WALLS, Ian. Migrating from Innovative Interfaces' Millennium to Koha: the NYU Health Sciences Libraries' experiences. OCLC Systems \& Services: International Digital Library Perspectives, v. 27, n. 1, p. 51-56, 2011. DOI: 10.1108/10650751111106564. Disponível em: https://www.emerald.com/insight/content/doi/10.1108/10650751111106564/full/html.

Acesso em: 04 jul. 2019.

WEITZEL, Simone da Rocha. Origem e fundamentos do processo de desenvolvimento de coleções no Brasil: estudo de caso da Biblioteca Nacional. In: ENCONTRO NACIONAL DE PESQUISA EM CIÊNCIAS DA INFORMAÇÃO, 5., 2009, João Pessoa. Anais [...] . João Pessoa: ENANCIB, 2009, [sem paginação]. Disponível em: http://enancib.ibict.br/index.php/enancib/xenancib/paper/viewFile/3278/2404. Acesso em: 31 jul. 2019.

YANG, Sharon Q.; HOFMANN, Melissa A. The next generation library catalog: a comparative study of the OPACs of Koha, Evergreen, and Voyager. Information Technology and Libraries, v. 29, n. 3, p. 141, 2010. Disponível em:

https://ejournals.bc.edu/ojs/index.php/ital/article/viewFile/3139/27. Acesso em: 31 jul. 2019.

YAZICIOGLU, Mengu. Koha usage in large and branched libraries. 2018. 1 video (26 min). Publicado pelo canal ByWater Solution. Disponível em:https://www.youtube.com/watch?v=z_0WldWlkA\&list=PLV_OXyJ1D3BgcRtxrjVkCBXjSt7Dr1qKy\&index=21\&t=0s. Acesso em. 31 jul. 2019.

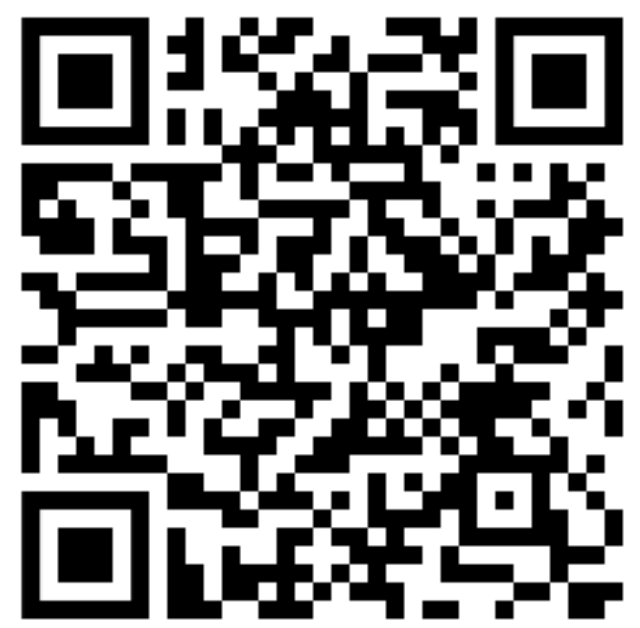

